\title{
Exploration of Building Information Modelling (BIM) Application: An Understanding Among Quantity Surveyor in Malaysia
}

\author{
*Nadzirah Zainordin, Zamzarina Md Judyar, Nur Syahirah Zafarull , Nor Azizah \\ Zalin
}

Center of Building \& Resilient Development, Faculty of Engineering and Built

Environment \& IT, SEGi University

* nadzirahzainordin@ @segi.edu.my

\begin{abstract}
This study begins with a broad literature review to understand the Building Information Modelling (BIM) concept. Quantity Surveyors star as an influential role as qualified, trained, and proficient in dealing with glitches relating to construction expenditure, supervision, and consultation in the construction industry. When the task is getting crucial, an assistant from technology may help faster and smoother the process and task. This study aims to investigate an understanding of the application of BIM among Quantity Surveyor in Malaysia. According to the Board of Quantity Surveyors, Malaysia's official website, 101 registered Quantity Surveying Consultant firms were in 2018. This study targeted 1000 persons from different firms and expected to respond from at least 278 persons due to time constraints. The other criteria of the respondents include years of experience in the industry. Quantity Surveying Consultant firms would be the most suitable people to answer a questionnaire survey for this study. The registered Quantity Surveying Consultant firms are very well proficient in the quantity surveying practice and services. Therefore, by choosing Quantity Surveying Consultant firms to be the respondent may help in getting the most consistent answer and higher accuracy of the exploration of Quantity Surveyors productivity by adopting the Building Information Modelling (BIM) concept in Quantity Surveyor, which will further enhance the awareness of benefits of BIM to the Quantity Surveyor profession itself.
\end{abstract}

Keywords: Building Information Modelling, Quantity Surveyor, Understandin 


\section{Introduction}

According to the Economy of Malaysia retrieved from Wikipedia, Malaysia has a substantial construction trade of more than RM102.2 billion (US $\$ 32$ billion). The most significant percentage stake was inbalance by the construction of non-residential buildings, which recorded 34.6 percent. The issues happen due to the civil engineering sub-sector (30.6\%), residential buildings (29.7\%), and unique trades $(5.1 \%)$. Some of the project players contributing to the construction industry are Contractors, Engineers, Designers/Architects, Quantity Surveyors, and Project Managers (Fanous 2012). Quantity Surveyors star as an influential role as qualified, trained, and proficient in dealing with glitches relating to construction expenditure, supervision, and consultation in the construction industry (Aje and Awodele 2007, A.E. Oke, I.O. Timothy, A.I. Olaniyi 2010). The role of a Quantity Surveyor includes preliminary cost advice, approximate cost estimate, cost planning, Bills of Quantities, procurement/tendering process, cost control, and measurements and quantifications (Fanous 2012).

Building Information Modelling (BIM) get influenced by the improved quantity surveying practice (Vineeth Raphael, 2014). BIM is the advancement and practice of a computer software exhibit to replicate a facility's construction and manoeuvre. The subsequent prototype, a Building Information Model, is a data-rich, object adapted intellectual and parametric illustration of the facility from where interpretations and data applicable to numerous users' essentials obtained and evaluated to produce data that be able to be exploited to make resolutions and develop the procedure of producing the facility (American General Contractors, 2006, Evelyn Ai Lin Teo, George Ofori, Imelda Krisiani Tjandra and Hanjoon Kim, 2015).

The utilisation of Building Information Modelling (BIM) in the construction industry has been studied. It has proven to provide more benefits to improve industry (Evelyn Ai Lin Teo, George Ofori, Imelda Krisiani Tjandra, and Hanjoon Kim, 2015). Several factors stop BIM from being implemented as the universal tool to be widely used in the construction industry in Malaysia.

Based on the Royal Institution of Chartered Surveyors BIM survey, numerous quantity surveyors are still unconscious of BIM, and only insignificant amounts (10\%) were retrieved to benefit from BIM (Matthews, 2011b). Hence, quantity surveyors 
need more exposure to this new technology, which will help them keep up with other industry experts' pace to conserve their competitiveness within the industry. Quantity surveyor consultant firms can expose their employees with new technology and adopt them into the quantity surveying practice.

Apart from that, a substantial extent of information has affected on BIM adoption and implementation challenges. Hurdles such as expense, guidance, interoperability, and modifications in the whole design process are often found all over the numerous information and, as such, appear substantial in setting back the implementation of BIM in the industry (Yan, H., \& Damian, P. (2008) \& Liu, R., Issa, R.R.A. \& Olbina, S., 2010). Therefore, large-scale projects with a long time frame and high amount of contract will be prioritized in the usage of BIM application, and a big firm will be more prioritized in the usage of BIM application than small firms with small projects that generate small incomes.

However, the complexity of building works thrown quantity surveyors through hassles, and clients turn to dismissal with the conventional ways of quantity surveyors' practice. Quantity surveyors must move away from uneconomical methods. Precise quantities can be quickly extracted directly from BIM (Vineeth Raphael, Jennifer Priyanka, 2014). Along these lines, quantity surveyors should understand the concept of BIM and its' abilities. Quantity surveyors should also be aware of client needs, which is to move on from the conventional method of quantity surveying practice to utilising the BIM concept in the industry to increase the industry's productivity.

There is always room for improvement in minimizing the difficulties of adopting BIM application in quantity surveying practice. The Malaysian construction industry needs to be parallel with other successful countries that have implemented technology usage in their industry. Quantity surveyors' practice in Malaysia must expose themselves with technology to increase productivity among them, leading to a better performance in the industry. Therefore, this research has to explore the BIM concept among Quantity Surveyor in Malaysia. 


\section{An emerging of building information modelling (BIM) with quantity surveyor practices}

Table 1.1 below shows the criteria of the BIM concept, which help increase the productivity of quantity surveyors in quantity surveying practice in Malaysia. The most popular criteria that the authors mentioned is cost estimating, which is referred four times by Exactal Technologies (2010), Muzvimwe (2011), Chung, et al., (2012), Mitchell (2012). Then, followed by system coordination, which is referred three times by Chung et al. (2012), Mitchell (2012) \& Thurairajah \& Goucher (2013). After that, design assistance and constructability, which is referred three times by Azhar et al. (2012), Thurairajah \& Goucher (2013) \& Wong Phui Fong, Hafez Salleh \& Faizul Azli Mohd Rahim (2014). Last but not least, fast and accurate cost estimation, which is referred three times by Exactal Technologies (2010), Azhar, et al., (2012) \& Mitchell (2012).

BIM can extract a construction project is costing from the earliest design, which explains project scope at the fundamental stage and determines the budget (Exactal Technologies, 2010). The BIM application can make the cost appraisal be prepared briefly from the feasibility stage (Mitchell, 2012). The preliminary cost plan can be obtained by extorting quantities from the model (Chung et al.,. 2012). BIM also adopts 5D, which means 4D plus “cost." It combines design with costing, scheduling, and estimating, which accelerates Bills of Quantities production, derived output rates, and worker costs (Muzimwe, 2011). 
Table 1. Criteria of BIM related to QS practice

\begin{tabular}{|c|c|c|c|c|c|c|c|c|c|}
\hline $\begin{array}{l}\text { No } \\
\text {. }\end{array}$ & Criteria & 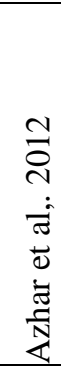 & 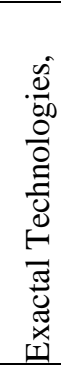 & 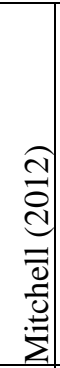 & 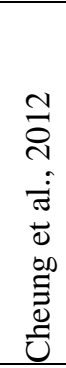 & 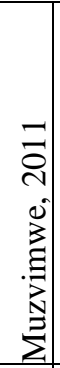 & 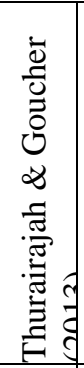 & 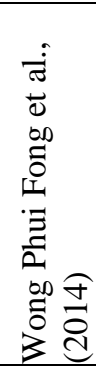 & 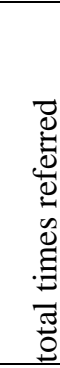 \\
\hline 1 & $\begin{array}{l}\text { Design assistance and } \\
\text { constructability }\end{array}$ & / & & & & & / & / & 3 \\
\hline 2 & Scheduling and sequencing & & & & & 1 & & & 1 \\
\hline 3 & Cost estimating & & l & I & I & I & & & 4 \\
\hline 4 & System coordination & & & l & l & & I & & 3 \\
\hline 5 & Clash detection & & & & & & 1 & & 1 \\
\hline 6 & Parametric modelling & 1 & & / & & & & & 2 \\
\hline 7 & Participatory approach & / & & & & & & & 1 \\
\hline 8 & $\begin{array}{l}\text { Problems/Errors } \\
\text { identification }\end{array}$ & & & & & & & l & 1 \\
\hline 9 & $\begin{array}{l}\text { Fast \& Accurate cost } \\
\text { estimate }\end{array}$ & I & I & / & & & & & 3 \\
\hline
\end{tabular}

BIM allows the changes in construction design and generates precise cost estimations for various design options without difficulty (Mitchell, 2012). The brilliant information organisation permits data to accumulate in a dominant synchronized model (Chung et al.,. 2012). BIM also offers the cost implication of design transformations, which can be produced effortlessly without the need to do remeasurement (Thurairajah \& Goucher, 2013).

BIM ensures that the designs are constructed within the time and budget given. It allows the visualization of the illustrated construction project in order to get a better understanding of the whole construction project. (Azhar et al.,. 2012; Thurairajah \& Goucher, 2013). Apart from that, BIM also helps identify possible problems in a simulated environment before it comes to actual construction (Wong Phui Fong, Hafez Salleh \& Faizul Azli Mohd Rahim, 2014). BIM is demonstrated as a good system in the construction industry, which has empowered experts to lower improbabilities and accomplish the successful accomplishment. Cost checking performed briefly to guarantee that all items are captured (Exactal Technologies, 
2010). Parametric modification technology synchronizes transformations \& sustains regularity at all times (Azhar et al.,. 2012). Permits quick and precise evaluation of various design alternatives for the client to select the best possible design that meets their requirements (Mitchell, 2012).

Based on the criteria mentioned, BIM application helps practitioners make the construction industry smoother and less complicated. BIM offers more detailed, fast, and precise cost estimates for the construction industry. It assists construction practitioners with good system coordination and better construction design and constructability.

\section{Methodology}

In a nutshell, a literature review was carried out to explore the understanding of Quantity Surveying and Building Information Modelling (BIM), the advantages of BIM, and connect it to the adoption of BIM in Quantity Surveying Practice in Malaysia.

The collection of data has been divided into preliminary and secondary data. The preliminary data is collected through questionnaire surveys (i.e., Google Form) from the targeted respondents in the construction industry, and the results of the questionnaire surveys will be evaluated. The secondary data is derived from articles, journals, research papers, reports, conference papers, and resources available from the internet.

The population sample was restricted to the Kuala Lumpur area only. The research sample consists of 1000 respondents who undertook questionnaires. Apart from that, the research sample is restricted to quantity surveyors from quantity surveying consultant firms only. According to Krejcie \& Morgan (1970), it is a table that helps the researcher determine the sample size according to a specific number of populations. Therefore, the figure has been round up the total quantity surveyors as the population size, $\mathrm{N}=1000$, sample size (S) will be 278 . In other words, by sending out one thousand questionnaires, the expected to receive feedback from at least a total number of 278 respondents. These participants are experts whom they had significant experience in their respective fields of work. 
All data assembled from secondary data information and preliminary data information will be broke down together. From both data information collected, the goals and the point of the research will be fulfilled.

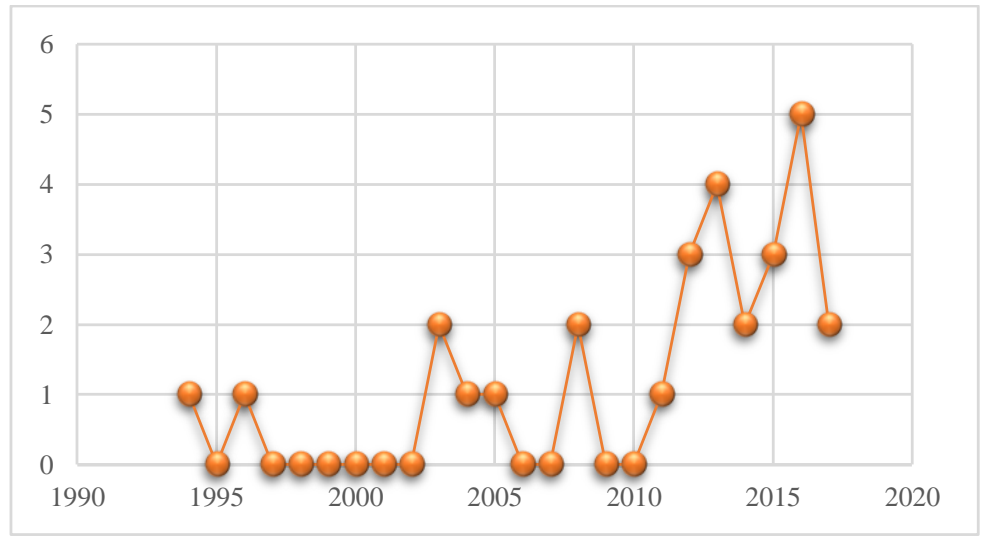

Figure 1. Referred journal

There are 28 journal papers have been used in finding the suitable literature review to support this research. A descriptive study using 28 related research papers within 15 years interval from 1994 to 2017 . Which the numbers of papers versus years can be reflect from Figure 1 below.

Two hundred eighty sets of structured questionnaires were sent to respondents who have experienced BIM usage in their projects. The frequency analysis has been used to further analysed the data and findings.

\section{Analysis and findings}

By referring to Figure 1, the age group is divided into four groups - first, the age range of 20-29 years. Then age group range 30 to 39 years old. Then age group 40 to 49 years old. Furthermore, the age group range above 50 years old. Figure 1 shows the percentage of the age range of respondents. There $67.86 \%$ (190 people) from the age range of $20-29$ years old. About $21.43 \%$ ( 60 people) from the age group of 30 to 39 years old. Then, $7.14 \%$ (20 people) from the age group $40-49$ years old and $3.57 \%$ (10 people) from the age above 50 . 


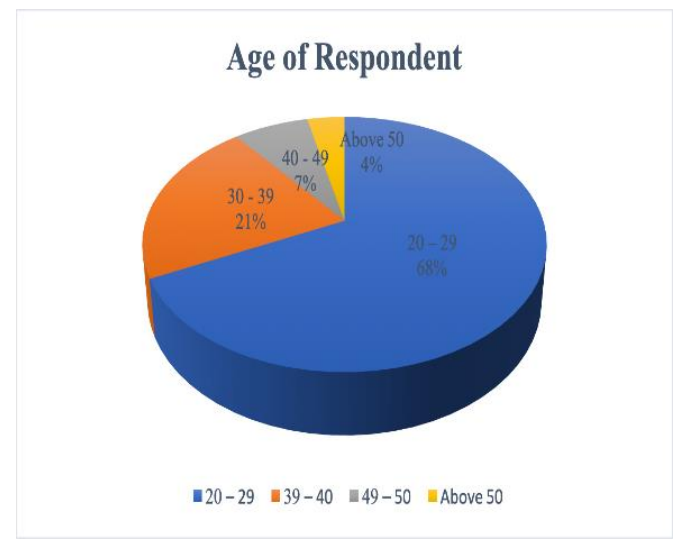

Figure 2. Respondents age

Figure 2 shows the percentage of the respondents' years of using BIM. 57.14\% (160 people) have used BIM for two years to 5 years, and $42.86 \%$ (120 people) have used BIM for less than two years. None of the respondents have ever used BIM for more than five years.

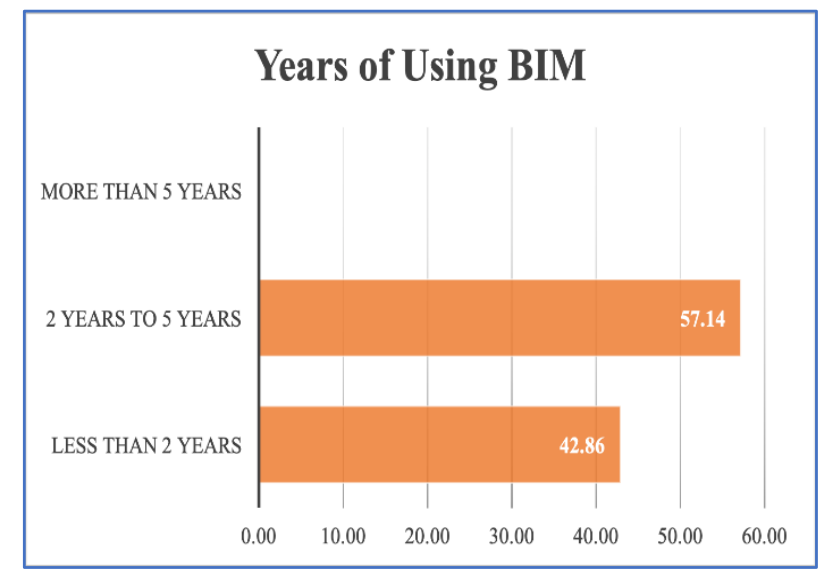

Figure 3. Years of respondent using BIM

Figure 3 below shows the analysis of the result from the respondent on perception towards Building Information Modelling. There is 7 perception highlighted which are $\mathrm{BIM}$ is an innovative and method that has rapidly converted the technique construction are visualised, designed, built and functioned; BIM is a digital portrayal of a construction's geometric and non-geometric data also stated as a dependable, common information resource to decide on a facility during its lifecycle; BIM can be 
defined as a platform to design simulated models to portrayal all physical and functional features of construction by using IT tools; BIM in innovative tools and method that has rapidly converted the technique construction are visualised, designed, built and functioned; BIM is a digital portrayal of a construction's geometric and nongeometric data.

From the table, a higher level of agreement goes to "BIM can be defined as a platform to design simulated models to portray all physical and functional features of construction by using IT tools" with 90 frequency. Based on the reading from min, median, and mode, the highest number goes to "agree."

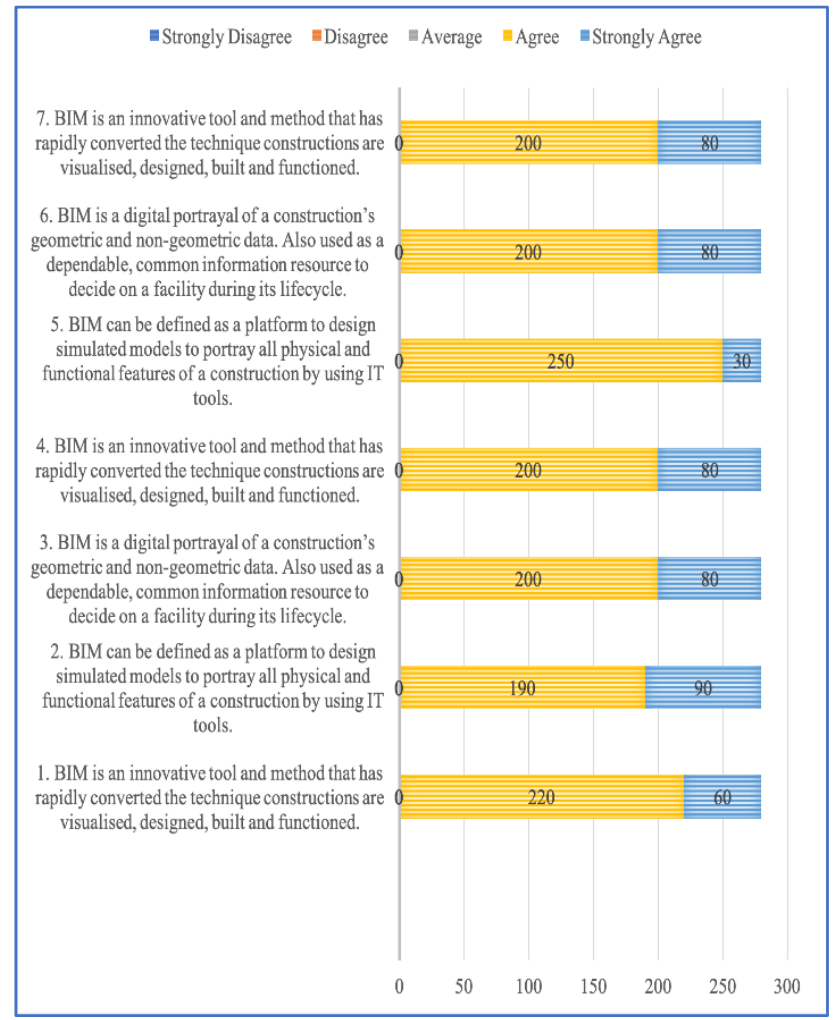

Figure 4. Respondent understanding towards BIM

\section{Conclusion}

As a conclusion of the literature review and results and findings, quantity surveying is related to cost, financial management, and contracts in the construction project. Quantity surveyors are well-trained professionals who have expertise in 
advising construction costs, making them also known as Construction Economist or Cost Manager in the construction industry. At the same time, BIM is an innovative platform and method to design simulated models and display construction's geometric and non-geometric data through digital portrayal. It offers participation from architects, planners, and contractors in order to be more representative. BIM consists of more than a digital illustration of geometry; includes physical and functional features of a construction.

BIM application helps practitioners in making the construction industry smoother and less complicated. BIM offers more detailed, fast, and precise cost estimates for the construction industry. It assists construction practitioners with good system coordination and better construction design and constructability. BIM is the perfect benchmark to reduce improbabilities and increase the proficiency of the construction process. It provides a transparent visualization of design to verify all possible improbabilities so that the design can be enhanced at the initial stage to save time, cost, and produce better quality.

\section{References}

A.E. Oke, I.O. Timothy, A.I. Olaniyi, Perception of Construction Professionals to The Performance of Nigerian Quantity Surveyors, Federal University of Technology, Akure Nigeria, 2010.

Vineeth R., Jennifer P. (2014), Role of Building Information Modelling (BIM) in Quantity Surveying Practice, Anna University, Chennai, India.

Evelyn A. L. T, George O., Imelda K. T., Hanjoon K. (2015), The Potential of Building Information Modelling (BIM) for Improving Productivity in Singapore Construction”, National University of Singapore, Singapore.

Board of QS Malaysia (BQSM). https://bqsm.gov.my/index.php/en/qs-registry2/registered-qs-practices

Gayathri N., Himal S. J., Ranadewa K. A. T. O. (2013), Building Information Modelling and Future Quantity Surveyor's Practice in Sri Lankan Construction Industry, University of Moratuwa, Sri Lanka.

Siti S. H. (2016), The Motivation of Quantity Surveyors in the Malaysian Construction Industry for Improved Job Performance, The University of Salford, Salford, United Kingdom,

Yeshwanth B. R. (2015), The Changing Face of Quantity Surveying Practice in Construction Industry, Deakin University. 
Timothy O., Olawumi, Olaleke A., Ayegun (2016), Are Quantity Surveyors Competent to Value for Civil Engineering Works? Evaluating QSs' Competencies and Militating Factors, The Federal University of Technology, Akure, Nigeria.

Salman A, Malik K., Tayyab M. (2013), Building Information Modelling (BIM): Now and Beyond, Auburn University, USA \& RMIT University, Australia.

Aftab H. M., Ismail A. R., Irfana M., Nur I. A. (2014), BIM in Malaysian Construction Industry: Status, Advantages, Barriers and Strategies to Enhance the Implementation Level, Universiti Tun Hussein Onn, Johor, Malaysia.

Christine G. (2010), The Influence of Building Information Modelling on The Quantity Surveying Profession.

Hassan H. E. (2016), Comparing Qualitative and Quantitative Approach, Walden University; University of the Rockies.

Fahmeena O. M. (2016), Qualitative vs. Quantitative Design, Northcentral University. 